\title{
EL SANEAMIENTO EN LA COMPRAVENTA DE BIENES DE CONSUMO
}

\author{
WARRANTY OF TITLE AND RIGHT OF POSSESSION IN THE CONTRACT \\ OF SALE AND PURCHASE OF CONSUMER GOODS
}

\author{
DR. JEAN-PIERRE SORTAIS*
}

Analizaremos en esta ponencia el saneamiento en la compraventa de bienes de consumo, para lo cual será necesario tomar del Derecho común, específicamente, del contrato de compraventa algunas ideas.

"El vendedor esta obligado a la entrega y saneamiento de la cosa objeto de la venta" según el Código Civil español en su artículo 1461, el cual se inspira del artículo 1603 de su homólogo francés. Entregar y sanear: tales son las obligaciones principales del vendedor.

Uno y otro, el francés como el español, son herederos del Derecho Romano y esto justifica el planteamiento del problema que surge cuando el comprador tiene algún motivo de quejarse de la ejecución por el vendedor, de sus obligaciones.

Puede acontecer que el comprador esté decepcionado porque el objeto entregado no corresponde a la cosa que él tenía en vista cuando se celebró el contrato y esto puede ocurrir de dos $-y$ aún de tres- maneras distintas:

- $\quad$ o bien se equivocó, hubo de su parte un error en cuanto al objeto mismo del contrato;

- o bien el objeto entregado no es el que había sido convenido: el comprador recibió lo que el Derecho Romano llamaba un "aliud", o sea una cosa distinta de la convenida;

- o bien la cosa entregada es la conveni$\mathrm{da}$, pero presenta defectos que hacen su uso más difícil, más costoso o, en el peor de los casos, lo impiden.

\footnotetext{
*Agrégé des Facultés de droit, Professeur honoraire à l'Université de Lausanne. Charla dictada en la Facultad de Derecho de la Pontificia Universidad Católica de Chile a los profesores y alumnos de Derecho Civil y Romano, el día 28 de agosto de 2008.
}

De modo que se ven claramente tres tipos de remedios posibles, según el origen de la queja del comprador:

- $\quad$ si puede convencer al juez que hubo un error, podrá tratar de obtener la nulidad del contrato por vicio de su consentimiento; a no ser que los dos se hubiesen equivocado, lo que corresponde al caso del "error-obstáculo": los consentimientos de las dos partes no podían encontrarse puesto que cada uno concernía a un objeto diferente;

- $\quad$ si la cosa que recibió no corresponde a la que se había previsto en el contrato, el comprador podrá sostener que el vendedor no ha cumplido debidamente su obligación de entrega; la falta de conformidad entre lo convenido y lo cumplido debe permitir al comprador demandar al vendedor cuya responsabilidad contractual podrá ser declarada;

- si la cosa entregada presenta defectos que disminuyen su utilidad, entonces es una cuestión de saneamiento la que se plantea: el vendedor debe su garantía y el Código Civil prevé el saneamiento por los defectos o gravámenes ocultos de la cosa vendida. (Ver art. 1484 a 1499 del Código Civil español y 1641 a 1657 del Código Civil francés: las acciones que corresponden al saneamiento (acción redhibitoria y acción estimatoria o "quanti minoris") son llamadas genéricamente acciones edilicias.)

Desde un punto de vista teórico, la situación es clarísima: las tres posibilidades son distintas y a cada una le corresponde su propio remedio. Sin embargo, de hecho y en el terreno práctico, las diferencias no son tan pronun- 
ciadas y a veces uno puede vacilar; ¿fue una equivocación de parte del comprador o bien es el vendedor quien no cumplió debidamente su obligación de entrega? Sobre todo, el vicio oculto puede ser difícil distinguir de la falta de conformidad; ¿puede el defecto o la imperfección de la cosa entregada ser compatible con una ejecución exacta de la obligación de entrega? La distinción es sutil, pero real.

Y ahí se encuentra la paradoja: para tratar situaciones que pueden ser vecinas una de otra, el derecho francés instituye tres acciones -acción en nulidad, acción en responsabilidad contractual y acción en garantíaque obedecen a principios diferentes; de modo que para resolver lo que puede llamarse un "concurso de acciones" (V. O. TOURNAFOND, Les prétendus concours d'actions et le contrat de vente, D.1989.Chron.237; D. BOULANGER, Erreur, non conformité, vice caché: la fin d'une confusion, JCP 1996.Edit.Not.I.1585 et Ch. RADE, L'autonomie de l'action en garantie des vices cachés, JCP 1997.I.4009.), los jueces -con la ambición de conseguir un resultado práctico que sea justo- escogieron el remedio en función de su régimen más adecuado.

Sin embargo, esto hubo de evolucionar en el derecho francés: esta evolución se hizo bajo varias influencias entre las cuales la europea es sobresaliente, de modo que nuestro camino nos conducirá del derecho francés al derecho europeo.

En una segunda parte, procuraré resumir el planteamiento del problema de la trasposición de la directiva europea al derecho francés, lo que nos hará recorrer el camino en la dirección opuesta: del derecho europeo al derecho francés.

\section{LA EVOLUCIÓN DEL DERECHO FRANCÉS O DEL DERECHO FRANCÉS AL DERECHO EUROPEO}

Si uno procura resumir la evolución del derecho francés frente al problema del saneamiento, empieza por notar las dificultades que suscitó la distinción de las tres acciones en estrados, más arriba señaladas, y observar lo que fue la reacción de los tribunales en aquella situación.
¿Cómo se habría de enfrentar a estas dificultades? Aquí importa subrayar que, hoy más que nunca, los sistemas jurídicos no están aislados; el derecho francés está bajo la influencia de otras fuentes de derecho, especialmente la fuente europea. ¿Cómo se va a enfrentar al problema en esta perspectiva? Trataré este aspecto después de exponer, en primer lugar, las dificultades.

\section{A. LAS Dificultades}

$\mathrm{Si}$, como ya lo vimos, las tres situaciones descritas (error, falta de conformidad y saneamiento) son vecinas y a veces su diferenciación muy difícil, el problema se hace aun más agudo si uno tiene en cuenta sus regímenes respectivos, especialmente cuando se plantea la cuestión del plazo en el cual el comprador tiene que dirigirse al tribunal:

cuando el comprador pide la nulidad del contrato por error, el plazo era y todavía es de cinco años (solía ser de diez años hasta 1968 cuando el art. 1 1305 del código fue reformado y el plazo reducido a cinco años); en todo caso, el punto de partida es el día en el que se descubre el error, lo que puede ser varios meses y aun varios años después de la celebración del contrato;

si el comprador pretende que el vendedor no ha cumplido debidamente su obligación de entrega, porque el objeto entregado no está conforme a lo convenido, es una cuestión de responsabilidad contractual que se plantea. El plazo para actuar, según el derecho común, era de treinta años; pero si el litigio opone a dos comerciantes, el plazo se reducía a diez años, lo que era la duración normal de la prescripción en materia mercantil; la misma duración de diez años se aplicaba a los actos mixtos, es decir entre un comerciante y una persona privada (Cass.com. 29 de febrero de 1984, Bull.civ.IV. $\mathrm{n}^{\circ}$ 84.) tal como un consumidor;

ahora, si se trata de vicios ocultos, encontrábamos uno de los preceptos más famosos del Código Civil pues decía el 
art. 1648 que el comprador debía actuar en un "plazo breve" sin más precisión. ¿Es una cuestión de semanas, de meses o de años? El Código Civil francés no lo decía (desde este punto de vista, la solución del Código español es mucho mejor: según el art. 1490 las acciones por saneamiento "se extinguirán a los seis meses, contados desde la entrega de la cosa vendida").

Que el plazo haya de ser breve se entiende fácilmente, porque ¡cómo asegurarse que el vicio es contemporáneo a la venta si ha transcurrido demasiado tiempo? Este "breve plazo" que era un ejemplo único, era ciertamente específico del saneamiento por vicios ocultos: ajeno a la acción en resolución por falta de conformidad, la cual implica el incumplimiento de la obligación de entrega (Cass.com. 3 de mayo de 1983, Gaz.Pal.1983.Panor.240, obs. J. DUPICHOT y Cass.civ. 1er, 13 de enero de 1993, Bull.civ.I $\mathrm{n}^{\circ}$ 7.) y aquí no se debe olvidar que la falta de conformidad se entiende de la no conformidad a lo convenido.

Como ustedes lo pudieron notar, he tenido que emplear el pretérito imperfecto: es que el famoso "plazo breve" hoy es una cosa del pasado, pertenece al museo de las antigüedades jurídicas: aprovechando la transposición al derecho francés de una directiva comunitaria europea, la ordenanza $n^{\circ}$ 2005-136 del 17 de febrero 2005 (JO 18 février 2005, p. 2278, comentario por A.M. LEROYER, RTD.Civ.2005.483, $\mathrm{n}^{\circ}$ 4.) que modificó el artículo 1648 del Código Civil, de modo que hoy se prevé un plazo especial de dos años.

$\mathrm{Si}$, a propósito de la acción en resolución por falta de conformidad, la no conformidad se entiende como la no conformidad a lo convenido, la no conformidad de la cosa a su destinación normal pertenece más bien al saneamiento por vicios ocultos: según el art. 1641 del código francés (que corresponde al art. 1484 de su homólogo español).

El vendedor responde de los defectos de la cosa que "la hacen impropia para el uso a que se la destina o que disminuyen de tal modo este uso que, de haberlos conocido, el comprador no la habría adquirido o habría dado menos precio por ella". La frontera es muy difícil de delinear entre las dos situaciones, tanto de no conformidad a lo convenido y de no conformidad a la destinación normal, y se puede aplicar al derecho francés lo que escribe un autor español tratando de su propio derecho: "Es una tarea ardua la de determinar con precisión la protección de que goza el consumidor que adquiere una cosa defectuosa, ya que existen a su disposición una pluralidad de remedios jurídicos cuya exacta coordinación es objeto de interminables debates en la doctrina científica" (J.R. de VERDA y BEAMONTE, El régimen de conformidad y garantía en los productos y servicios en el manual "Derecho de consumo" de M.J. REYES LOPEZ, 2è. edición, Valencia 2002. En cuanto a los interminables debates, lo mismo se puede notar en la doctrina francesa. Basta con citar algunas de las crónicas sobre este tema: Ch.ATIAS, L'obligation de délivrance conforme, D.1991.Chron.1-3; L'équilibre renaissant de la vente, D.1993.Chron. 1-3; La distinction du vice caché et de la con-conformité, D.1993.Chron. 265-266; BENABENT, A., Conformité et vices cachés dans la vente: l'éclaircie, D.1994.Chron.115-116; CASAUXLABRUNeE, L., Vice caché et défaut de conformité: propos non conformistes sur une distinction viciée, D.1999.Chron.1-7; JOURDAIN, P., Conformité, vices cachés et sécurité, Gaz.Pal.1994.II.Doctr.826; LE TOURNEAU, Ph., Conformités et garanties dans la vente d'objets mobiliers corporels, Rev.tr.dr.com.1980.231-276. TOURNAFOND, O., Les prétendus concours d'actions et le contrat de vente (erreur sur la substance, défaut de conformité, vice caché), D.1989.Chron.237-244; VINEY, G., Le triomphe du "bref délai" de l'art. 1648 code civil et le démantèlement de la protection de l'acheteur en cas de vente d'une chose défectueuse, JCP 1994.I.3773, $\mathrm{n}^{\circ}$ 12.); de la misma manera, una especialista francesa habla de una "amplia panoplia de acciones".

La jurisprudencia, de una manera general, trata de favorecer al adquiriente: este último a menudo tropezaba contra el obstáculo del "plazo breve", hoy de 2 años, y ello acarreó nue- 
va jurisprudencia. Una de las más recientes sentencias consistió en decidir que, cuando un acto interrumpe la prescripción, desde luego ello ya se habrá cumplido en tiempo útil -es decir durante el "breve plazo"- por lo que es la duración normal de la prescripción la que se aplica; por ejemplo, si un recurso de urgencia es intentado pidiendo el nombramiento de un perito, el plazo normal es de 5 años, que transcurrirá a partir del día en que el perito remite su ponencia (Cass.civ.1er, 21 de octubre de 1997, JCP 1998.II.10063, comentario MONLOUNGUI, C., D.Aff.1997.1418; compar. Contra: Paris, 2 de septiembre de 1998, D.Aff.1998.1564, com. J.F.); esto viene o más bien venía a confundir interrupción e interversión del plazo.

Aquí hay lugar para dos comentarios muy importantes:

- cuando se habla de "plazo normal", esto quería decir, hasta hace poco, un plazo de 10 a 30 años. Hoy ya no es el caso: desde la ley $n^{\circ} 2008-561$ del 17 de junio 2008, el plazo de 5 años es el derecho común cuando se trata de acciones personales o mobiliares; derecho común que no se aplica a los vicios ocultos puesto que, en esta materia, hay -desde el año 2005- un plazo especial de 2 años.

- $\quad$ además, la ley del 17 de junio de 2008 deroga la antigua confusión entre interrupción e interversión del plazo puesto que, según el nuevo art. 2231 del Código Civil, cuando viene a cesar la interrupción, "corre un nuevo plazo de misma naturaleza" -es decir de misma duración- "que el antiguo".

Tal es la situación actual en derecho francés: la distinción de los tres tipos de acciones tenía una importancia decisiva y llevaba consigo consecuencias prácticas trascendentales. Aún así, desde un punto de vista teórico, nada ha cambiado, se debe reconocer que las consecuencias prácticas ya no son las que solían ser. Tanto mejor si, de las leyes de 2005 y 2008, resulta una simplificación apreciable.

La extensión y la ampliación de la obligación de entrega conforme eran una manera de proteger al comprador; y, en caso necesario, de acoger más fácilmente la responsabilidad contractual del vendedor, verdaderamente una obligación de seguridad (Cass.civ. 1 ${ }^{\text {er }}, 15$ de octubre de 1996, D.197.som.287, obs. JOURDAIN, P., et som.348, obs. BRUn, Ph., Bull.civ.I.n ${ }^{\circ}$ 354, D.Aff.1996.1288, JCP 1997.I.4125, n 13, obs. VINEY, G.)

Cabe destacar que, desde hace unos años, la jurisprudencia del Tribunal Supremo considera esta obligación de seguridad como autónoma respecto al saneamiento de vicios ocultos (Cass.civ.1 ${ }^{\text {er }}, 11$ de junio 1991, Bull.civ.I.n 201, D.1993.Som.241, obs. TOURNAFOnD, O., Rev.trim.dr.civ. 1992.114, obs. JOURDAIN, P.) y, en este tipo de solución, hay que ver una influencia del Derecho europeo. Quizá el remedio a las dificultades se encontrara en el Derecho europeo.

B. El Remedio: ¿El Derecho europeo? Cuando se habla de Derecho europeo, son varios textos que hay que tener en cuenta en la materia:

- $\quad$ la directiva CEE 85-374 del 25 de julio de 1985 sobre la responsabilidad por los productos defectuosos;

- la directiva 92-59 del 29 de junio de 1992 sobre seguridad de los productos; y sobre todo la directiva 1999-44-CE del Parlamento y del Consejo del 25 de mayo de 1999 (JOCE $\mathrm{n}^{\circ} \mathrm{L} / 171,7 \mathrm{de}$ julio 1999, p.12.) sobre determinados aspectos de la venta y las garantías de los bienes de consumo.

Hasta ahora hemos hablado de compraventa, de vendedor y de comprador: y es que el consumidor es a menudo un comprador. En adelante se tratará únicamente del consumidor como tal (V. S. CHILlon, Le droit communautaire de la consommation après les traités de Maastricht et d'Amsterdam, Louvain la neuve (Centre de droit de la consommation édit.1999) y Vers un code européen de la consommation (Actes et débats du Colloque organisé à Lyyon les 12 et 13 décembre 1997 (Bruylant edit. 1998). Adde: BIANCA, M.C., GRUNDMAN, S., STIJINS, S., La directive communautaire sur la vente, Bruylant édit. 2004.). 
La directiva de 1999 sobre determinados aspectos de la venta y las garantías de los bienes de consumo lleva consigo innovaciones de primera importancia:

- en cuanto a los conceptos, la directiva rechaza la distinción clásica entre falta de conformidad y vicio oculto: en vez de esa distinción, prevé una noción única que es una clase de síntesis de las dos nociones que el art. 2-1 de la directiva presenta así: "El vendedor estará obligado a entregar al consumidor un bien que sea conforme al contrato". Y tal como lo dice un autor: "La principal aportación de la directiva consiste en haber acuñado un concepto unitario, el de "conformidad" que abarca todos los posibles defectos de la cosa comprada que supongan una desviación del programa contractual". (J.R. de VERDA y BEAMONTE, op. cit. (supra nota 9), spéc. p.476.)

- otra aportación de importancia concierne a los remedios: mientras con las acciones edilicias, el consumidor puede obtener o bien la resolución del contrato, o bien la disminución del precio, en la directiva las soluciones son más variadas puesto que la directiva permite al consumidor demandar la reparación o la substitución de la cosa defectuosa, sin perjuicio naturalmente de la indemnización de daños y perjuicios.

La ambición de esta directiva es establecer un zócalo mínimo común de preceptos equitativos para la venta de bienes de consumo. Y como siempre a propósito de directivas comunitarias, los jueces nacionales deben conformar sus sentencias a los preceptos de la directiva.

Aquella directiva ha dado lugar recientemente a jurisprudencia y acá se debe señalar una decisión reciente del tribunal de justicia de las Comunidades europeas del 17 de abril de 2008 (CJCE, 17 abril 2008, asunto C-404/ 06, Quelle AG c/ Bundesverband der Verbraucherzentralen und verbraucherbande, Re.jur.com.2008.306, obs. RAYNOUARD, A.): este fallo tuvo que dar una interpretación del artículo 3 de la directiva 1999-44, según la cual el consumidor puede, en caso de falta de conformidad del objeto vendido, "exigir la reparación del bien o su reemplazo, en ambos casos sin gastos". La cuestión que se planteaba era la siguiente: ¿puede, o no, una ley nacional autorizar al vendedor a exigir del consumidor una indemnización para compensar el uso del bien del que ha gozado hasta su reemplazo por otro bien? El artículo 15 de la directiva prevé que, en caso de reembolso (que es un caso distinto), el reembolso puede dar lugar a reducción para tener en cuenta el uso que el consumidor ha tenido del bien desde su entrega. El tribunal rechaza la posibilidad de razonar por analogía a partir de este caso vecino, pero distinto, $y$ adoptando una postura deliberadamente favorable al consumidor resuelve la cuestión por la negativa: en caso de reemplazo del bien vendido, el vendedor no puede exigir ninguna indemnización del consumidor.

Si miramos al origen de la directiva, hay que remitirse indudablemente a la Convención internacional de Viena de 1980 sobre la compraventa internacional de mercancías, es decir, un instrumento destinado esencialmente a relaciones de tipo mercantil. Mas, si nos movemos hacia el futuro, el destino de una directiva es que se traduzca en las legislaciones de los Estados miembros de la Unión Europea (en el caso presente, la directiva 99-44 del 25 de mayo de 1999 debía ser transpuesta para el 10 de enero de 2002 a más tardar).

\section{DEL DERECHO EUROPEO AL DERECHO FRANCÉS}

Con la directiva de 1999 tenemos la definición de un régimen que define el nivel mínimo que debe prevalecer en las legislaciones de la Unión Europea.

Y aquí la tentación es de decir: ¡felices españoles y franceses! Porque, después de haber expuesto una comparación entre el régimen de la garantía comunitaria de la directiva, y el de la ley española (se trata de la LGDCU o ley general para la defensa de los consumidores y usuarios), un autor dice: "cabe pensar que la trasposición de la directiva requiere pocos 
retoques en la regulación española que es más favorecedora del consumidor que la norma comunitaria" (J.R. de VERDA y BEAMONTE, $o p$. et loc. cit.).

Esta última observación vale también para el Derecho francés. Sin embargo, la cuestión de la trasposición de la directiva suscita una controversia de gran amplitud entre dos tesis: algunos quisieran generalizar las soluciones de la directiva, mientras otros, opinan que la trasposición debe ser limitada a su propio objeto, o sea, a la protección del consumidor sin tocar al derecho común.

Vamos a tratar de resumir los términos de esta controversia que suscitó numerosos estudios.

\section{A) HaCia UnA TRANSPOSICIÓN AMPLIA}

El ministerio de justicia encargó a una comisión preparar un anteproyecto para la trasposición de la directiva. Esta comisión preparó una ponencia en la cual se pronunciaba a favor de una reforma general del derecho común de la compraventa: le pareció oportuno aprovechar la ocasión de la trasposición de la directiva para proceder a una revisión del Código Civil, suprimiendo las antiguas acciones edilicias y adoptando el sistema de la directiva, generalizándolo a todas las clases de ventas. Se puede leer en la presentación de la ponencia que es "una ocasión única de darle al derecho francés las modificaciones que exigen su modernización y su adaptación a la situación económica y social actual".

El mérito esencial de esta solución es, sin argumentos en contra posibles, que constituye una simplificación. Es la misma norma, o más bien la misma serie de normas, que se aplican cualquiera que sea el comprador -poco importa que sea, o no, un consumidor- y cualquiera que sea el bien comprado. ¿Es ese argumento suficiente para convencer a todos? No, naturalmente, y hay también el precio que pagar para disfrutar por esta "ventaja". Y si hay partidarios de la generalización, esta también tiene adversarios. (VINEY, G., Rapport général du groupe de travail sur l'intégration en droit français de la directive 1999-44 du Parlement européen et du Conseil du 25 mai 1999 sur certains aspects de la vente, La documentation française édit. V-. aussi VineY, G., Quel domaine assigner à la loi de transposition de la directive européenne sur la vente? JCP 2002.I.258 y, del mismo autor: Retour sur la transposition de la directive du 25 mai 1999, D.2002.Chron.3162. Adde: Jourdain, P., Transposition de la directive sur la vente: ne pas manquer une occasion de progrès, D.2003.4 y MAZEAUD, D., La parole est à la défense ... D.2003.6 y RAYNARD, J., Rev.trim.dr.civ.2002.871, $\mathrm{n}^{\circ}$ 6.)

\section{B) A FAVOR DE UNA TRASPOSICIÓN LIMITADA \\ Los autores favorables a una trasposi-} ción limitada alegan que la solución propuesta por la comisión: a) desconoce la especificidad del derecho de consumo y, b) extiende inoportunamente a todos los compradores -aún en las ventas entre dos profesionales o dos personas privadas- una protección que el legislador quería limitar a los consumidores en sus relaciones con los profesionales. $\mathrm{Y}$, sobre todo, esta extensión induce una limitación de la libertad contractual fuera del dominio propio de la directiva.

Además, es de subrayar que una trasposición limitada favorece a los intereses mismos de los consumidores. ¿Por qué? Porque -además de la protección mínima propia de la directiva- los consumidores seguirían estando bajo la protección del Código Civil y, como lo señalé antes, el Código Civil favorece más al comprador en ciertos aspectos; de modo que suprimir la protección tradicional traería un empobrecimiento de los derechos del consumidor. (PAISANT, V. G. y LEVENEUR, L.,Quelle transposition pour la directive du 25 mai 1999 sur les garanties dans la vente de biens de consommation? JCP.2002.I.135, TOURNAFOND, O., La transposition de la directive du 25 mai 1999, D.2001.Chron.3051; LEVENEUR, L., Les contrats de consommation et le droit européen, Contrats,concurr.et consom., mars 2002; TOURNAFOND, O., De la transposition de la directive du 25 mai 1999 à la réforme du code civil, D.2002.Chron.2883; R. FAMILY, Erreur, non conformité, vice caché: état des questions à l'heure de la transposition de 
la directive du 25 mai 1999, más de 3 años, que claramente escogió la soluContrats,concurr,yconsom., Avril 2002, ción de una trasposición limitada. (V. O. Chron.4; GHOZI, A., La conformité (in TOURNAFOND, La nouvelle "garantie de conFaut-il recodifier le droit de la consommation? formité " des consommateurs: commentaire de Economica édit. 2002, p.1039 y MAINGUY, l'ordonnance $n^{\circ}$ 2005-136 du 17 février 2005, Md., Propos dissidents sur la transposition de D.2005.Chron.1557 y PAISANT, G., La transla directive du 25 mai 1999 sur certains as- position de la directive du 25 mai 1999 sur la pects de la vente et de garanties des biens de consommation, JCP 2002.I.183.)

Finalmente, la directiva europea de 1999 fue transpuesta por una ordenanza del 17 de febrero 2005, o sea con un retraso de garantie dans la vente des biens de consommation, JCP.2005.I.146.)

Muchas gracias a la Facultad de Derecho de la Pontificia Universidad Católica de Chile por su cordial invitación. Buenos días. 